\title{
Is there a U-shaped association between physical activity and falling in older persons?
}

\author{
G. M. E. E. Peeters • N. M. van Schoor • \\ S. M. F. Pluijm • D. J. H. Deeg • P. Lips
}

Received: 5 June 2009 / Accepted: 4 August 2009 / Published online: 15 September 2009

(C) The Author(s) 2009. This article is published with open access at Springerlink.com

\begin{abstract}
Summary This study tests whether the relationship between physical activity and (recurrent) falling is U-shaped. Among 1,337 community-dwelling older persons, no evidence for a nonlinear association was found. If all older persons increase their physical activity level with 100 units, $4 \%$ may be prevented to become recurrent fallers.

Introduction Previous studies suggest a U-shaped relationship between physical activity and falling. This study tests this hypothesis and examines whether this relationship is modified by level of physical functioning.

Methods Community-dwelling persons (65+) from the Longitudinal Aging Study Amsterdam (LASA) were prospectively followed on falls for 3 years after baseline assessment in 1995/1996 $(n=1,337)$. Outcome measures were time to first fall and time to recurrent falling. The LASA Physical Activity Questionnaire was used to calculate physical activity in minutes per day weighted for intensity (range 0-2000). Physical functioning was measured with physical performance tests and self reported functional limitations. Confounders were age, sex, body mass index, chronic diseases, psychotropic medication,
\end{abstract}

G. M. E. E. Peeters · N. M. van Schoor · D. J. H. Deeg • P. Lips Department of Epidemiology and Biostatistics, EMGO Institute for Health and Care Research, VU University Medical Center, Amsterdam, the Netherlands

S. M. F. Pluijm

Department of Public Health, Erasmus MC,

Rotterdam, the Netherlands

P. Lips $(\bowtie)$

Department of Internal Medicine, section Endocrinology,

VU University Medical Center,

Postbus 7057, 1007 MB Amsterdam, the Netherlands

e-mail: p.lips@vumc.nl cognitive functioning, depressive symptoms, and fear of falling.

Results No evidence for a nonlinear association was found ( $p$ for physical activity ${ }^{2}>0.20$ ). No significant association was found between physical activity and time to first fall. An increase in physical activity of 100 units led to a $4 \%$ decrease in risk of recurrent falling (adjusted hazard ratio $0.96,95 \%$ confidence interval $0.92,0.99$ ). No interactions with physical performance or functional limitations were found $(p>0.50)$.

Conclusions The hypothesized U-shaped relationship between physical activity and falling could not be confirmed. At higher levels of physical activity, the risk of recurrent falling decreased, while no association was found with fall risk.

Keywords Accidental falls · Aged · Functional limitations · Physical activity Physical performance

\section{Introduction}

Falling is a major cause of injury and disablement in older persons. About $30 \%$ of older community-dwelling persons falls once a year, and $15 \%$ falls at least twice a year $[1,2]$. The consequences of falling vary from no consequences at all to major injuries and fear of falling [2-5]. About 5-10\% of all falls result in a fracture, whereas $90 \%$ of all fractures are attributable to falls $[6,7]$.

Physical (in)activity has been identified as an important risk factor of falling in older persons [8-10]. Both low and high levels of physical activity have been associated with an increased fall risk [8, 11-14]. Inactivity is associated with frailty and muscle weakness $[15,16]$, which are wellknown risk factors for falling. Highly active persons are more often exposed to hazardous situations, such as 
reaching into overhead cupboards or playing tennis [9, 13]. Some evidence for a U-shaped relationship between physical activity and fall risk was found in a classification tree for predicting recurrent falling. In this study, an increased fall risk was found both in more frail persons who had a fall history and two or more functional limitations and in persons with a good physical performance who had high levels of physical activity [17]. Current clinical guidelines and health care policies recommend physical activity among older persons because of its beneficial effects on many health outcomes, such as cardiovascular functioning and bone quality [18, 19]. However, if there is indeed a U-shaped relationship, falling may be an adverse effect of these recommendations, and it may be necessary to reconsider these guidelines and policies.

To our knowledge, only three studies examined the relationship between physical activity and falls, with physical activity in three or more categories, and thus, giving insight in the shape of the relationship [12-14]. However, none of the studies tested the shape of the relationship using correct statistical techniques, and none of these studies used a validated physical activity questionnaire in combination with prospectively measured falls in a general population of community-dwelling older persons. Furthermore, the relationship between physical activity and falling may differ for well and poor functioning persons. Active older persons may have an increased fall risk due to an incongruence of what they are able to do and what they actually do [20]. Interactions with physical activity and both leg extension power [12] and using a walking aid [13] have been found in the relationship with (recurrent) falling. Both leg power and using a walking aid are indicators of physical functioning, but do not measure the entire concept. The current study overcomes the limitations of previous studies.

This study examined the relationship between physical activity and time to first fall and time to recurrent falling in community-dwelling older persons. We hypothesized that the relationship between physical activity and (recurrent) falling would be U-shaped: both low and high levels of physical activity were expected to be associated with an increased fall risk. Also, we expected that highly active older persons with poor physical functioning had the highest fall risk.

\section{Methods}

\section{Subjects}

This study was performed within the Longitudinal Aging Study Amsterdam (LASA), an ongoing interdisciplinary cohort study on predictors and consequences of changes in physical, cognitive, emotional, and social functioning in older persons [21]. A random sample of older men and women stratified for age, sex, and expected 5-year mortality was drawn from the population registries of 11 municipalities in the Netherlands. The sampling and data collection procedures have been described in detail elsewhere [21, 22]. The sample for this study consisted of 1,509 participants $(65+$ years) in the second cycle $(1995 / 1996)$. In total, 1,427 participants had complete fall follow-up, of whom 1,342 participants had complete data (54 had missing values on physical activity and 31 on any of the confounders). Five additional participants were considered outliers and excluded from the analysis because of unlikely high values for physical activity. These five outliers all reported eight or more hours of light and heavy housekeeping activities per day, which is likely to be due to over reporting. Moreover, their physical activity levels were more than four standard deviations away from the sample mean. In total, 1,337 participants were included in the analysis. The Medical Ethics Committee approved the study, and all participants signed informed consent.

\section{Falls and recurrent falling}

Falls were prospectively assessed during 3 years following the baseline interview in 1995/1996 using a fall calendar [23]. Participants were asked to tick every week whether or not they had fallen. Once every 3 months, the calendar page was mailed to the institute. If the calendar procedure was too complicated, if the page was not received (even after a reminder), or if the page was completed incorrectly, the participants were contacted per telephone. Proxies were contacted if participants were unable to respond. A fall was defined as "an unintentional change in position resulting in coming to rest at a lower level or on the ground" [24]. Recurrent falling was defined as "falling at least two times within 6 months during the 3-year fall follow-up" [25]. An occasional faller was defined as a person who fell at least once during follow-up, but who did not meet the criteria for recurrent falling. Time from baseline to the date of the first fall was determined as time to first fall; time from baseline to the date of the second fall within a 6-month period was determined as the time to recurrent falling. Participants who were deceased, could not be contacted, or refused further participation during follow-up were included in the analyses until time of drop-out.

\section{Physical activity}

Physical activity was measured at baseline (1995/1996) using the validated LASA Physical Activity Questionnaire [26], an interviewer-administered questionnaire which estimates the frequency and duration of participation in activities in the previous 2 weeks. The activities were walking, cycling, light, and heavy household work and first 
and second sport. To take the intensity of the activities into account, metabolic equivalent (MET) scores were assigned to each activity based on published MET scores lists [27, 28]. For each activity, the frequency, duration in minutes, and MET score were multiplied and then divided by 14 days (i.e., $($ frequency $\times$ duration $\times$ MET) $/ 14$ ). The minutes spent per activity per day were summed to a total physical activity score (minutes/day $\times$ MET). For example, a participant who walks outside for $60 \mathrm{~min}$ four times per 2 weeks $(4 \times 60 \times 3.5 / 14=60)$ and does light household work for $30 \mathrm{~min}$ per day $(14 \times 30 \times$ $2.5 / 14=75$ ) has a physical activity score of $135 \mathrm{~min} /$ day $\times$ MET.

Potential effect modifiers

Physical functioning was measured by physical performance and functional limitations. Physical performance was measured using the chair stands test (time needed to stand up from a chair and sit down for five times), the walk test (time needed to walk $3 \mathrm{~m}$, turn $180^{\circ}$, and walk back), and the tandem stand (the participant stands unsupported with one foot behind the other (heel against toe) up to $10 \mathrm{~s}$ ) $[23,29]$. In order to calculate a total physical performance score, the time needed for the chair stands and walk test were categorized into quartiles $(1=$ slowest, 4 = fastest). For the tandem stand, 2 points were scored when able to hold for 3 to $9 \mathrm{~s}$, and 4 points for $10 \mathrm{~s}$. For each test, the score of 0 was assigned when the participant was unable to complete the test. The three scores were summed (range 0-12), a score of 12 representing optimal physical performance. Functional limitations were assessed using a validated questionnaire about the degree of difficulty with climbing stairs, walking $5 \mathrm{~min}$ outdoors without resting, getting up and sitting down in a chair, dressing and undressing oneself, cutting one's toenails, and using own or public transportation [30]. The scores on these six items were dichotomized $(0=$ no difficulty, $1=$ at least some difficulty) and summed (range 0-6). A score of 6 indicates difficulties with all six activities.

We dichotomized both measures, because, in case of a significant interaction with physical activity, further analyses would have to be stratified into low and high physical functioning, and stratification for more than two groups would have severely decreased the power to detect a significant association between physical activity and fall risk. Physical performance was dichotomized using the median score of 7 as the cut-off value $(0-7$ vs $8-12)$. Functional limitations were dichotomized using the median score of 1 as a cut-off value ( 0 vs $\geq 1$ limitations).

\section{Confounders}

BMI (Body Mass Index) was calculated as weight (kilograms)/height (square meter). The number of chronic diseases was assessed using self-reports on chronic diseases, which included chronic nonspecific lung diseases, cardiac diseases, vascular diseases, stroke, diabetes mellitus, malignant neoplasms, and joint disorders (i.e., osteoarthritis and rheumatoid arthritis; range 0-7) [31]. Medication use was assessed by recording the names of the medications directly from the containers. Use of psychotropic medication (antipsychotics, antidepressants, anxiolytics, or hypnotics) was dichotomized as nonusers versus users. Cognitive functioning was measured using the mini-mental state examination (MMSE, range 0-30) [32]. Depressive symptoms were assessed using the Center for Epidemiologic StudiesDepression Scale (CES-D, range 0-60). Fear of falling was measured using a modified version of the Falls Efficacy Scale (FES) [33]. The participants reported how concerned $(0=$ not concerned, $3=$ very concerned) about falling they were while carrying out ten activities of daily living (range $0-30$ ).

\section{Statistics}

Differences in baseline characteristics for nonfallers, occasional fallers, and recurrent fallers and were tested using analysis of variance for normally distributed continuous variables, Kruskall-Wallis tests for skewed continuous variables, and Chi-squared tests for dichotomous variables. To examine the association between physical activity and time to first and recurrent falls, hazard ratios (HR) and 95\% confidence intervals $(95 \% \mathrm{CI})$ were calculated using the Cox proportional hazards model. The analyses were performed univariately and with adjustment for age, sex, chronic diseases, BMI, MMSE, depressive symptoms, psychotropic medication, and fear of falling. First, a quadratic term of physical activity (physical activity ${ }^{2}$ ) was included to assess a potential nonlinear relationship. Second, to test effect modification by physical performance (physical activity $\times$ physical performance) and functional limitations (physical activity $\times$ functional limitations), interaction terms were included in separate models. No colinearity between physical activity and physical performance or functional limitations was found $(r<0.21)$. To test for nonlinearity and interaction, the difference in $-2 \log$ likelihood was tested using $\mathrm{Chi}^{2}$-test $(p<0.10)$. Third, if an interaction term was significant, analyses were stratified by physical performance or functional limitations. $P$ values were based on two-sided tests and were considered statistically significant at $p<0.05$. All analyses were conducted in 2008/2009 using SPSS software (SPSS Inc., Chicago, version 15.0.2).

\section{Results}

As compared with responders, nonresponders were older, had lower BMI, more health problems, poorer cognitive 
functioning, more fear of falling, poorer physical performance, were less active ( $p$ for all characteristics $\leq 0.01$ ), and tended to be more often recurrent fallers $(p=0.08)$. In total, 1,337 participants were included, of whom 167 participants (12\%) dropped out during 3 years of follow-up.

During 3 years, 740 participants $(55.3 \%)$ reported at least one fall. Table 1 shows the baseline characteristics for nonfallers $(n=597)$, occasional fallers $(n=410)$, and recurrent fallers $(n=330)$. The three groups clearly differ in all baseline characteristics. The median physical activity in the total sample was $459 \mathrm{~min} /$ day $\times$ MET (interquartile range $=$ 259-703).

The $-2 \log$ likelihood between the model with the linear term of physical activity and the model with both the linear term and the quadratic term of physical activity was not significant for the outcome time to first fall $(p=0.20)$, indicating that there is no U-shaped association between physical activity and time to first fall. The interactions between physical activity and physical performance $(p=0.99)$ or functional limitations $(p=0.99)$ were not significant. Further analyses were not stratified for physical functioning. The linear association between physical activity and time to first fall was not significant: HR for an increase in physical activity of 100 units $=0.98,95 \%$ CI $0.96-1.01$ (Table 2). Adjustment for potential confounders did not change the association. Additional adjustment for physical performance or functional limitations did not change the association either ( $\mathrm{HR}=0.98,95 \% \mathrm{CI} 0.98,1.01$ for both models). In Fig. 1, we modeled the association between physical activity and time to first fall. To give insight in the actual data, we also presented the hazard ratios for physical activity in categories of 400-unit width against fall risk in Fig. 2.

The $-2 \log$ likelihood between the model with the linear term of physical activity and the model with both the linear term and the quadratic term of physical activity was not significant for the outcome time to recurrent falling $(p=0.82)$, indicating that there is no U-shaped association between physical activity and time to recurrent falling. The interactions between physical activity and physical performance $(p=0.72)$ or functional limitations $(p=0.59)$ were not significant. Further analyses were not stratified for physical functioning. A linear association between physical activity and time to recurrent falling was found: HR for an increase in physical activity of 100 units $=0.93,95 \%$ CI $0.90-0.97$ (Table 2). After adjustment for potential confounders, the association remained significant. After additional adjustment for physical performance or functional limitations, the association became not significant $(\mathrm{HR}=0.97,95 \% \mathrm{CI} 0.93$, 1.00 for both models). In Fig. 1, we modeled the association between physical activity and time to recurrent falling. To give insight in the actual data, physical activity in categories of 400 units was plotted against the risk of recurrent falling in Fig. 2. In contrast to the continuous analysis, no significant association between physical activity in categories and recurrent falling was found due to low numbers of participants, especially in the highest categories.

\section{Discussion}

This is the first study that examined whether the relationship between physical activity and (recurrent) falling was U-shaped. Testing did not confirm a U-shaped association between physical activity and time to first fall or time to recurrent falling. No statistically significant association was found between physical activity and falling, while an increase in physical activity of 100 units led to a $4 \%$ decrease in risk of recurrent falling. These associations were not modified by physical functioning.

In the literature, both low $[11,13,14]$ and high $[8,12]$ levels of physical activity have been associated with an increased fall risk. These findings have led to the hypothesis that the relationship between physical activity and fall risk may be U-shaped. The results of the current

Table 1 Baseline characteristics

BMI Body Mass Index, MMSE Mini-Mental State Examination

${ }^{a}$ Presented as percentages, differences tested using $\mathrm{chi}^{2}$-test

${ }^{\mathrm{b}}$ Presented as mean (standard deviation), differences tested using analysis of variance

${ }^{\mathrm{c}}$ Presented as median [interquartile range], differences tested using Kruskal-Wallis test

\begin{tabular}{|c|c|c|c|c|}
\hline & $\begin{array}{l}\text { Nonfallers } \\
n=597\end{array}$ & $\begin{array}{l}\text { Occasional fallers } \\
n=410\end{array}$ & $\begin{array}{l}\text { Recurrent fallers } \\
n=330\end{array}$ & $p$ value \\
\hline Sex $(\% \text { women })^{a}$ & 44.1 & 61.2 & 52.1 & $<0.001$ \\
\hline Age $(\text { years })^{\mathrm{b}}$ & $74.8(6.2)$ & $74.9(6.4)$ & $77.0(6.9)$ & $<0.001$ \\
\hline BMI $\left(\mathrm{kg} / \mathrm{m}^{2}\right)^{\mathrm{b}}$ & $26.9(4.2)$ & $27.4(4.5)$ & $26.5(4.0)$ & 0.009 \\
\hline Chronic diseases $(0-7)^{\mathrm{c}}$ & $1[0-2]$ & $1[0-2]$ & $1[1,2]$ & 0.01 \\
\hline Psychotropic medicine $(\% \text { yes })^{\mathrm{a}}$ & 10.4 & 16.3 & 20.6 & $<0.001$ \\
\hline $\operatorname{MMSE}(0-30)^{\mathrm{c}}$ & 28 [26-29] & $28[26-29]$ & 27 [25-29] & 0.04 \\
\hline Depressive symptoms $(0-60)^{\mathrm{c}}$ & $5[2-10]$ & $6[2-11]$ & $8[4-14]$ & $<0.001$ \\
\hline Fear of falling $(0-30)^{\mathrm{c}}$ & $0[0-2]$ & $1[0-3]$ & $1[0-5]$ & $<0.001$ \\
\hline Physical activity $(0-2,000)^{\mathrm{c}}$ & $481[267-720]$ & $480[286-731]$ & $407[228-638]$ & 0.002 \\
\hline Physical performance $(0-12)^{\mathrm{c}}$ & $8[6-9]$ & $7[5-9]$ & $7[3-9]$ & $<0.001$ \\
\hline Functional limitations $(0-6)^{\mathrm{c}}$ & $1[0-2]$ & $1[0-2]$ & $1[0-3]$ & $<0.001$ \\
\hline
\end{tabular}


Table 2 The associations between physical activity and time to first fall and time to recurrent falling

\begin{tabular}{lccc}
\hline Model & HR & $95 \%$ CI & $p$ value \\
\hline Time to first fall & & & \\
$\quad$ Physical activity & 0.98 & $0.96-1.01$ & 0.13 \\
$\quad$ Physical activity + confounders & 0.98 & $0.96-1.00$ & 0.11 \\
Time to recurrent falling & & & \\
$\quad$ Physical activity & 0.93 & $0.90-0.97$ & $<0.001$ \\
Physical activity + confounders & 0.96 & $0.92-0.99$ & 0.02 \\
\hline
\end{tabular}

Hazard Ratios (HR) and 95\% Confidence Interval (95\%CI) are presented per 100 units (i.e., minutes per day $\times$ MET score) increase in physical activity. Confounders were age, sex, body mass index, chronic diseases, psychotropic medication, mini-mental state examination, depressive symptoms, and fear of falling

study do not support this hypothesis, neither with respect to falling nor with respect to recurrent falling. This is in line with other large cohort studies which reported either a gradual increase or decrease in risk ratios for higher physical activity categories $[12,14]$.

In this study, physical activity was not significantly associated with fall risk. Three other cohort studies reported an increased fall risk in men [12] and a decreased fall risk in women [14] or in persons living in a residential care setting [13] in higher physical activity categories as compared with the lowest category. Perhaps lack of an association in our study is due to an interaction with sex. However, the interaction term for physical activity by sex

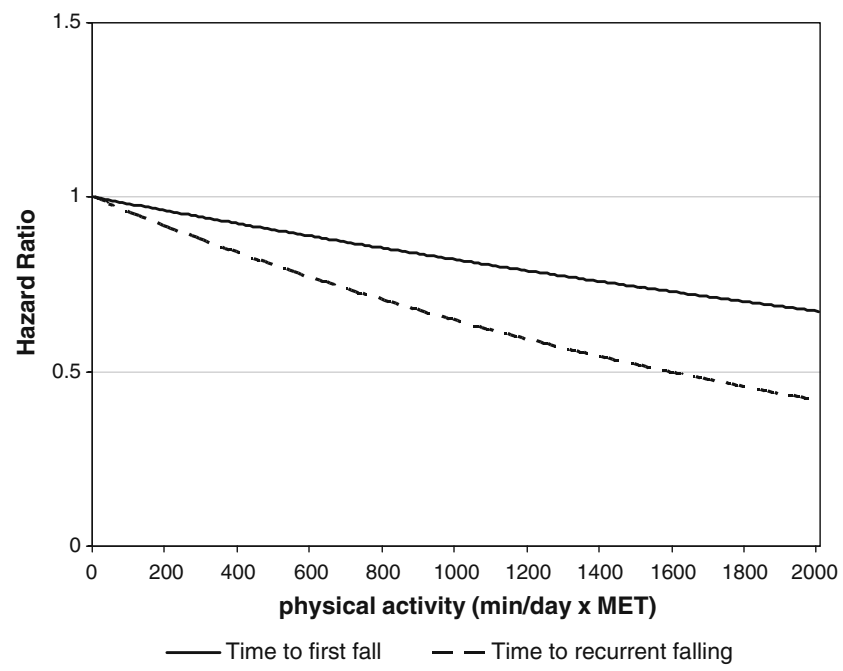

Fig. 1 The associations between physical activity and time to first fall and time to recurrent falling. The hazard ratios are plotted against physical activity (minutes/day $\times$ MET) after adjustment for age, sex, BMI, chronic diseases, psychotropic medication, MMSE, depressive symptoms, and fear of falling. The solid line represents the time to first fall $\left(\mathrm{HR}=\mathrm{EXP}\left(-1.98 \times 10^{-4} \times\right.\right.$ physical activity $\left.)\right)$, the dashed line represents the time to recurrent falling $\left(\mathrm{HR}=\operatorname{EXP}\left(-4.36 \times 10^{-4} \times\right.\right.$ physical activity)) was not significant $(p=0.89)$. A second explanation may be that in our study, participants with high levels of physical activity were underrepresented causing an underestimation of the actual relationship. However, our sample is representative for the community-dwelling older population in the Netherlands. Third, these three studies and the current study differed in population (men [12] vs women [14] vs residential care setting [13]), physical activity measures (validated questionnaires [12] vs operational definitions [14]), and outcome measures (4-month fall risk [12] vs proportion fallers [14]). It is likely that the contrasting findings are explained by differences in population and methodology.

The association between physical activity and recurrent falling has been studied only once before. A study among persons $(70+$ years) living in a residential care setting showed that the risk of recurrent falling decreased at higher levels of physical activity [13]. Our findings in communitydwelling older persons are in line with this study: an increase of 100 units led to a $4 \%$ lower risk of recurrent falling. One hundred units equal $30 \mathrm{~min}$ per day of walking, 20 in of swimming, or 40 min of billiards. Thus, if all older persons increase their physical activity level with 100 units, $4 \%$ may be prevented to become recurrent fallers. In addition, given the beneficial effects of physical activity on other health outcomes, it is important to observe that, other than expected in the literature, highly active persons do not have an increased risk of falling. Clinical trials are necessary to test whether increasing physical activity leads to a decrease in falls. Two recently published systematic reviews showed that multiple component exercise programs did reduce the fall risk in community-dwelling older

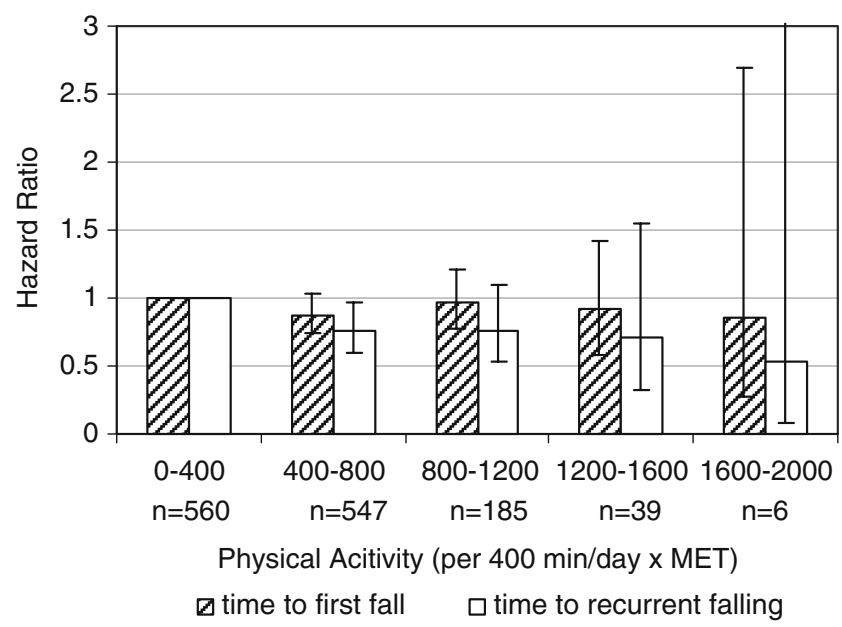

Fig. 2 The associations between physical activity (in categories) and time to first fall and time to recurrent falling. The hazard ratios for time to first fall and time to recurrent falling are plotted against physical activity (minutes/day $\times$ MET) in categories of 400 units after adjustment for age, sex, BMI, chronic diseases, psychotropic medication, MMSE, depressive symptoms, and fear of falling 
persons $[34,35]$. Increasing daily physical activity may be an important component of these exercise programs.

It has been suggested that in this type of study adjustment should be made for baseline mobility [9]. Like physical performance and functional limitations, mobility is a measure of physical functioning. In the current study, physical functioning did not modify the relationship between physical activity and (recurrent) falling. These results do not confirm the expectation that highly active persons with poor physical functioning fall more often due to an incongruence of what they are safely able to do and what they actually do. Possibly, older persons with poor physical function adapt the level and performance of activities to their abilities. However, physical functioning may not only act as an effect modifier or confounder, it may also be a mediator: physical activity and physical functioning could mutually affect each other and consequently the fall risk. In line with previous studies, we regarded physical functioning as a mediator and did not adjust for it in the final models $[12,13]$.

The strength of this study is the content of physical activity measured. Many physical activity questionnaires only assess the frequency or duration of a limited number of physical activities [9] and do not include light household activities, although these are important in older persons [36]. In addition, if intensity of activities is not included, the time spent doing activities may give a false impression of a person's level of activity. For example, a person with poor physical performance may need more time to finish the same activity than a person with adequate physical performance. We corrected for this phenomenon by weighing for the intensity of an activity. A limitation of this study is that physical activity was based on self-reports. However, this questionnaire has been validated for older persons [26]. Second, we excluded five participants with extremely high scores for physical activity (i.e., $>2,000 \mathrm{~min} /$ day $\times$ MET and $>4$ SD above the sample mean). When the analyses were repeated including these five participants, a marginally significant $U$-shaped association was observed between physical activity and time to first fall ( $p$ for physical activity $^{2}=0.07$ ), but not for time to recurrent falling $(p=0.32)$. Interactions with physical performance and functional limitations were not significant $(p>0.25)$. However, the number of participants in our study with such extremely high activity patterns is very small, and more research in this specific group is necessary before final conclusions can be drawn. Third, nonresponse analysis showed that those who were excluded from the analyses were less active and more often recurrent fallers. Thus, the relationship may be an underestimation of the actual relationship. Finally, physical activity was measured in $1995 / 1996$ and the fall follow-up ended in 1998/1999. The results may not be completely generalizable to the current community-dwelling population of 65 years and older. Cohort differences have been found in the level of physical activity: 55-64 year olds in 2002 were less active than the 55-64 year olds in 1992 [37]. To our knowledge, cohort differences for fall risk have not been reported. Replication of this study in a more recent dataset is necessary to confirm the association between physical activity and recurrent falling.

In conclusion, the hypothesized U-shaped relationship between physical activity and falling could not be confirmed. At higher levels of physical activity, the risk of recurrent falling decreased, while no association was found with fall risk in general. Moreover, the associations did not seem to be modified by level of physical functioning.

Acknowledgments This study is based on data from the LASA and is financially supported by the Dutch Ministry of Health, Welfare, and Sports.

Conflicts of interest None.

Open Access This article is distributed under the terms of the Creative Commons Attribution Noncommercial License which permits any noncommercial use, distribution, and reproduction in any medium, provided the original author(s) and source are credited.

\section{References}

1. Tromp AM, Smit JH, Deeg DJ, Bouter LM, Lips P (1998) Predictors for falls and fractures in the Longitudinal Aging Study Amsterdam. J Bone Miner Res 13(12):1932-1939

2. Tinetti ME, Speechley M, Ginter SF (1988) Risk factors for falls among elderly persons living in the community. N Engl J Med 319(26):1701-1707

3. Stel VS, Smit JH, Pluijm SM, Lips P (2004) Consequences of falling in older men and women and risk factors for health service use and functional decline. Age Ageing 33(1):58-65

4. Zijlstra GA, van Haastregt JC, van Eijk JT, van Rossum E, Stalenhoef PA, Kempen GI (2007) Prevalence and correlates of fear of falling, and associated avoidance of activity in the general population of community-living older people. Age Ageing 36 (3):304-309

5. Dunn JE, Rudberg MA, Furner SE, Cassel CK (1992) Mortality, disability, and falls in older persons: the role of underlying disease and disability. Am J Public Health 82(3):395-400

6. Parkkari J, Kannus P, Palvanen M, Natri A, Vainio J, Aho H, Vuori I, Jarvinen M (1999) Majority of hip fractures occur as a result of a fall and impact on the greater trochanter of the femur: a prospective controlled hip fracture study with 206 consecutive patients. Calcif Tissue Int 65(3):183-187

7. Youm T, Koval KJ, Kummer FJ, Zuckerman JD (1999) Do all hip fractures result from a fall? Am J Orthop 28(3):190-194

8. O'Loughlin JL, Robitaille Y, Boivin JF, Suissa S (1993) Incidence of and risk factors for falls and injurious falls among the community-dwelling elderly. Am J Epidemiol 137(3):342-354

9. Gregg EW, Pereira MA, Caspersen CJ (2000) Physical activity, falls, and fractures among older adults: a review of the epidemiologic evidence. J Am Geriatr Soc 48(8):883-893

10. Tinetti ME, Williams CS (1998) The effect of falls and fall injuries on functioning in community-dwelling older persons. J Gerontol A Biol Sci Med Sci 53(2):M112-M119 
11. Campbell AJ, Borrie MJ, Spears GF (1989) Risk factors for falls in a community-based prospective study of people 70 years and older. J Gerontol 44(4):M112-M117

12. Chan BK, Marshall LM, Winters KM, Faulkner KA, Schwartz AV, Orwoll ES (2007) Incident fall risk and physical activity and physical performance among older men: the Osteoporotic Fractures in Men Study. Am J Epidemiol 165(6):696-703

13. Graafmans WC, Lips P, Wijlhuizen GJ, Pluijm SM, Bouter LM (2003) Daily physical activity and the use of a walking aid in relation to falls in elderly people in a residential care setting. Z Gerontol Geriatr 36(1):23-28

14. Heesch KC, Byles JE, Brown WJ (2008) Prospective association between physical activity and falls in community-dwelling older women. J Epidemiol Community Health 62(5):421-426

15. Puts MT, Lips P, Deeg DJ (2005) Static and dynamic measures of frailty predicted decline in performance-based and self-reported physical functioning. J Clin Epidemiol 58(11):1188-1198

16. Szulc P, DuBoeuf F, Marchand F, Delmas PD (2004) Hormonal and lifestyle determinants of appendicular skeletal muscle mass in men: the MINOS study. Am J Clin Nutr 80(2):496-503

17. Stel VS, Pluijm SM, Deeg DJ, Smit JH, Bouter LM, Lips P (2003) A classification tree for predicting recurrent falling in communitydwelling older persons. J Am Geriatr Soc 51(10):1356-1364

18. 2008 Physical Activity Guidelines for Americans. http://www. health.gov/PAGuidelines/pdf/paguide.pdf. 2008

19. Kwaliteitsinstituut voor de Gezondheidszorg CBO (2002) Osteoporose. Tweede herziene richtlijn. Van Zuiden Communications B.V. Alphen aan den Rijn, the Netherlands

20. Graafmans WC, Ooms ME, Hofstee HM, Bezemer PD, Bouter LM, Lips P (1996) Falls in the elderly: a prospective study of risk factors and risk profiles. Am J Epidemiol 143(11):1129-1136

21. Deeg DJ, van Tilburg T, Smit JH, de Leeuw ED (2002) Attrition in the longitudinal aging study Amsterdam. The effect of differential inclusion in side studies. J Clin Epidemiol 55(4):319-328

22. Smith JH, de Vries MZ (1994) Procedures and results of the field work. In: Deeg DJH, Westendorp-de Serriere M (eds) Autonomy and well-being in the aging population I: report from the Longitudinal Aging Study Amsterdam 1992-1993. Vu University Press, Amsterdam, pp 7-13

23. Stel VS, Smit JH, Pluijm SM, Lips P (2003) Balance and mobility performance as treatable risk factors for recurrent falling in older persons. J Clin Epidemiol 56(7):659-668

24. Kellogg International Work (1987) The prevention of falls in later life. A report of the Kellogg International Work Group on the prevention of falls by the elderly. Dan Med Bull 34(Suppl 4):1-24

25. Pluijm SM, Smit JH, Tromp EA, Stel VS, Deeg DJ, Bouter LM, Lips P (2006) A risk profile for identifying community-dwelling elderly with a high risk of recurrent falling: results of a 3-year prospective study. Osteoporos Int 17(3):417-425
26. Stel VS, Smit JH, Pluijm SM, Visser M, Deeg DJ, Lips P (2004) Comparison of the LASA Physical Activity Questionnaire with a 7-day diary and pedometer. J Clin Epidemiol 57(3):252-258

27. Ainsworth BE, Haskell WL, Leon AS, Jacobs DR Jr, Montoye HJ, Sallis JF, Paffenbarger RS Jr (1993) Compendium of physical activities: classification of energy costs of human physical activities. Med Sci Sports Exerc 25(1):71-80

28. Caspersen CJ, Bloemberg BP, Saris WH, Merritt RK, Kromhout D (1991) The prevalence of selected physical activities and their relation with coronary heart disease risk factors in elderly men: the Zutphen Study, 1985. Am J Epidemiol 133(11):10781092

29. Guralnik JM, Simonsick EM, Ferrucci L, Glynn RJ, Berkman LF, Blazer DG, Scherr PA, Wallace RB (1994) A short physical performance battery assessing lower extremity function: association with self-reported disability and prediction of mortality and nursing home admission. J Gerontol 49(2):M85M94

30. Kriegsman DM, Deeg DJ, van Eijk JT, Penninx BW, Boeke AJ (1997) Do disease specific characteristics add to the explanation of mobility limitations in patients with different chronic diseases? A study in The Netherlands. J Epidemiol Community Health 51 (6):676-685

31. Kriegsman DM, Penninx BW, van Eijk JT, Boeke AJ, Deeg DJ (1996) Self-reports and general practitioner information on the presence of chronic diseases in community dwelling elderly. A study on the accuracy of patients' self-reports and on determinants of inaccuracy. J Clin Epidemiol 49(12):1407-1417

32. Folstein MF, Folstein SE, McHugh PR (1975) Mini-mental state. A practical method for grading the cognitive state of patients for the clinician. J Psychiatr Res 12(3):189-198

33. Tinetti ME, Richman D, Powell L (1990) Falls efficacy as a measure of fear of falling. J Gerontol 45(6):239-243

34. Gillespie LD, Robertson MC, Gillespie WJ, Lamb SE, Gates S, Cumming RG, Rowe BH. (2009) Interventions for preventing falls in older people living in the community. Cochrane Database of Syst Rev (2) CD007146. doi:10.1002/14651858.CD007146.pub2

35. Sherrington C, Whitney JC, Lord SR, Herbert RD, Cumming RG, Close JC (2008) Effective exercise for the prevention of falls: a systematic review and meta-analysis. J Am Geriatr Soc 56 (12):2234-2243

36. Jorstad-Stein EC, Hauer K, Becker C, Bonnefoy M, Nakash RA, Skelton DA, Lamb SE (2005) Suitability of physical activity questionnaires for older adults in fall-prevention trials: a systematic review. J Aging Phys Act 13(4):461-481

37. Visser M, Pluijm SM, van der Horst MH, Poppelaars JL, Deeg DJ (2005) Lifestyle of Dutch people aged 55-64 years less healthy in 2002/'03 than in 1992/'93. Ned Tijdschr Geneeskd 149(53):29732978 